\title{
Study of Factors Influencing the Transformation of Medical Staff's Well-being in the Context of the COVID-19 Pandemic
}

\author{
Julia Tokareva ${ }^{1, *}$, and Elena Lysenko ${ }^{1}$ \\ ${ }^{1}$ UrFU named after the first President of Russia B.N.Yeltsin, Department of Human Resources \\ management and Psychology, 620002 Yekaterinburg, Russian Federation
}

\begin{abstract}
Research background: The pandemic caused by COVID-19 is one of such situations that required urgent, anti-crisis solutions on organizing medical-care and support for the life of people. Special attention in scientific research of scientists from different countries is paid to medical workers, as the main participants in the elimination of the pandemic, whose external and internal working conditions have changed to a greater extent.

Purpose of the article: to investigate factors those affect the well-being of health care workers in the workplace during the COVID-19 pandemic.

Methods: The basis of the tools of empirical sociological research was the author's method of studying 3 groups of factors that affect the well-being of employees: informing of the situation associated with the pandemic, changes in the nature and conditions of work; specifics of working in remote mode in connection with the pandemic.

Findings \& Value added: The study revealed the importance of informing employees about the situation, as well as a high level of its reliability and timeliness. The most significant changes in the work were the need to control contacts, the use of special protective equipment and the appearance of a large number of stressful factors. The main consequence of working in a pandemic environment, both for employees working in the previous mode and for employees working in remote mode - is a decrease in the level of material well-being. The study of the transformation of work in remote mode, in addition to technical parameters, showed deterioration in working conditions and communication.
\end{abstract}

Keywords: extreme situation; pandemic COVID-19, medical staff; wellbeing in the workplace

JEL Classification: L26; M21; M29

\footnotetext{
* Corresponding author : e.v.lysenko@urfu.ru
} 


\section{Introduction}

A new coronavirus disease officially designated COVID-19 emerged as a cluster of unexplained cases of pneumonia in Wuhan, China and was declared a pandemic by the World Health Organization on March 11, 2020 [1], [2]. The epidemic of COVID-19 caused an international crisis [3] and affected all population groups as well as influenced the development of the society actualizing the problem of well-being of the working population [4]. The development of new forms of information support, sense of security, and control over the situation were caused by the fast spread of the virus. With the help of an interactive web-based panel (Aninteractiveweb-based), the aggregate data on the number of cases was updated every 15 minutes using DXY for all provinces in China and for other affected countries and regions. Moreover, the web-based panel has proved particularly effective for timing the first reported case of COVID-19 in new countries or regions [5]. Critical Care Practice for COVID-19 outbreak was proved effective in Lombardy, Italy [6].

It is obvious that in the XXI century infectious diseases have become one the major threats to society well-being, exposing the most vulnerable groups of population including children, healthcare workers and the elderly people [7], and, as a consequence, determining the wellbeing and attitude towards life of mankind in general.

Extreme and critical situations lead to numerous changes in the life of society and people, they make people adapt to them and make crucial decisions in order to ensure security, on the one hand, and preserve the vitality of society, on the other. The pandemic caused by COVID-19 is one of such situations that required urgent, anti-crisis solutions on organizing medical-care and support for the life of people [8].

Special attention in scientific research of scientists from different countries is paid to medical workers, as the main participants in the elimination of the pandemic, whose external and internal working conditions have changed to a greater extent. External working conditions are closely connected with the general changes in the work of organization, internal working conditions - are the changes in the specifics of work for employees occupying different positions, forms of professional interaction, taking into account the age and psychophysiological state of employees.

Treushnikova N.V. et al note that quarantine measures are difficult working conditions requiring the highest degree of mobilization and dedication from specialists of a medical institution [9]. New difficulties are constantly appearing; technical working conditions become more complicated. The principles and possibilities of interaction between doctors and their relatives or friends, acting as a resource for active life, are also changing.

Doctors fighting the epidemic face extreme conditions combining social and personal risks. We studied the impact of working relationships (organizational support, supervisornursing relationships and teamwork) on the involvement, well-being, organizational commitment and turnover intentions of nurses working in hospitals in Australia and the United States, and showed their impact on work performance in crisis working conditions [10].

The Union for Mental Health and the Scientific and Educational Centre for Modern Medical Technologies conducted an All-Russian survey on the psychological state of medical workers during the COVID-19 pandemic, which allowed us to identify three groups of factors that determine well-being.

The first factor not only according to opinion of the majority, but by the importance as well is sufficient awareness in a stressful situation [11]. The content side of the information is bilateral in nature, affecting the field of work organization and prevention of emotional burnout of a specialist, as well as the strategic goals of the organization, as a condition for the formation of prospects [12]. Any information should be given timely and precisely. Any 
distortion of reality entails distrust and a decrease in professional efficiency, which has been proven in virtual and real projects of organizational interaction [13].

The second factor influencing the well-being of medical workers is related to the stability of an organization, the preservation of guarantees, the retention of personnel and social prospects, organizational care [14].

The appearance of such well-being factor is not accidental since the problem of preserving jobs, social guarantees in the context of the coronavirus pandemic is more urgent than ever. Various researches in the field of labor organization found that the basic changes in professional activity of medical workers are: switching to remote work; reduction of working time; termination of the activity of a medical organization due to quarantine; transition to irregular working hours (work 24/7); expansion of functionality; introduction of additional measures related to the prevention of infection. This list of activities shows only general changes and does not reflect all the innovations in a medical organization in connection with the fight against the pandemic. It is known that the work security and stability, clear functionality and professional tasks create a basis for confidence and professionalism. The changes in the schedule, working hours, the closure of some medical organizations (mostly private clinics), and the transition to part-time work create the preconditions for stuff reductions, staff rotation and changes in approaches to the provision of social guarantees.

The third factor is the attitude of medical workers to their professional activity as well as their loyalty and professionalism in transformed working conditions.

Sanitary and epidemiological measures, quarantine lasting more than 95 days, a large percentage of sick medical workers, radical changes in the list of tasks of medical workers, expanding functionality and limiting contact, lack of communication and professional interaction affect the level of loyalty and attitude to work. Lack of opportunities for proper rest and recuperation, communication with the loved ones lead to emotional exhaustion and the formation of mental stress [15]. Motivation in the form of material incentive acts as a condition for involvement, but only if the need for this incentive is relevant and does not rank second after rest. According to Ermolaeva S., well-being as well as employee engagement are formed mostly from the conditions available in the organization to meet professional and personal needs that have potential opportunities for career and personal growth [16].

\section{Methodology}

The purpose of the present research is to study the factors affecting well-being of medical workers on their workplace during the pandemic of COVID-19.

The basis of the empirical and sociological research in the form of questionnaire was formed by the author's method of studying the factors affecting the well-being of employees. The questionnaire contained the following significant blocks:

$\boldsymbol{I}^{\text {st }}$ block - the assessment of the level of awareness of the pandemic situation in the aspects: sufficiency/reliability/timeliness of information on the development of the situation with COVID-19;

$2^{\text {nd }}$ block - well-being of employees in connection with the changes in specifics of work; 2 groups of respondents are eliminated: those who work as usual, and those who was transferred to remote work. The follow-up analysis is performed;

$3^{\text {rd }}$ block - changes in the specifics of remote work caused by the pandemic.

The study was based on the research of multidisciplinary medical center providing medical services of a wide range of activities and located in Yekaterinburg, Ural Federal District, Russian Federation.

The respondents are doctors and medical personnel; the total number - 35 people. 


\section{Findings}

The research findings for the selected information blocks allow us to identify the following significant trends.

Block 1 - the assessment of the level of awareness of the pandemic situation in the aspects: sufficiency/reliability/timeliness of information on the development of the situation with COVID-19

A) The level of awareness of the pandemic situation among the respondents is high: the majority (about $90 \%$ ) of the respondents are sufficiently $(31 \%)$ aware of the situation connected with COVID-19 and more (51\%). (Fig. 1)

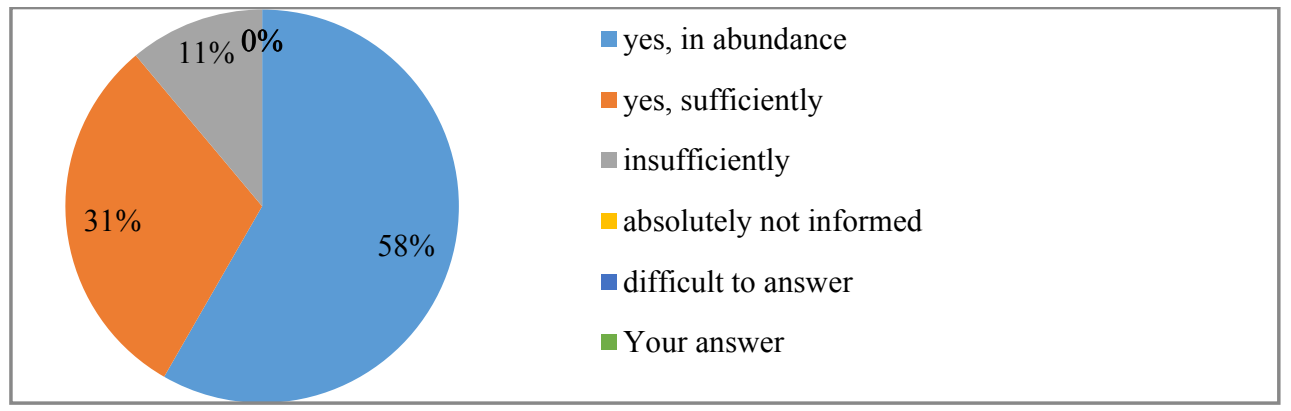

Fig. 1. The level of awareness of the pandemic situation

Source: own research, May 2020 (Fig. 2)

B) The majority of the respondents $(69 \%)$ does not question the timeliness of information.

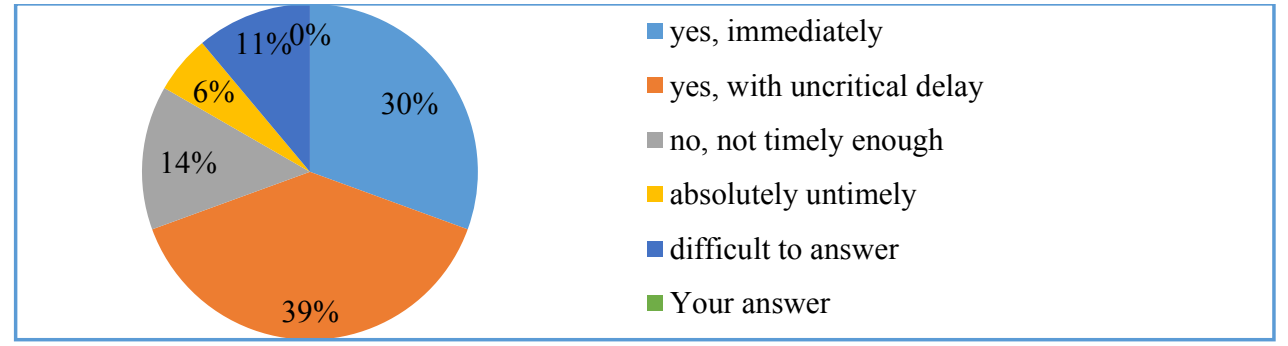

Fig. 2. The timeliness of information of the pandemic situation Source: own research, May 2020

C) Meanwhile, the reliability of information is questioned: up to $52 \%$ of the respondents believe that information is more or less kept secret or distorted. (Fig. 3).

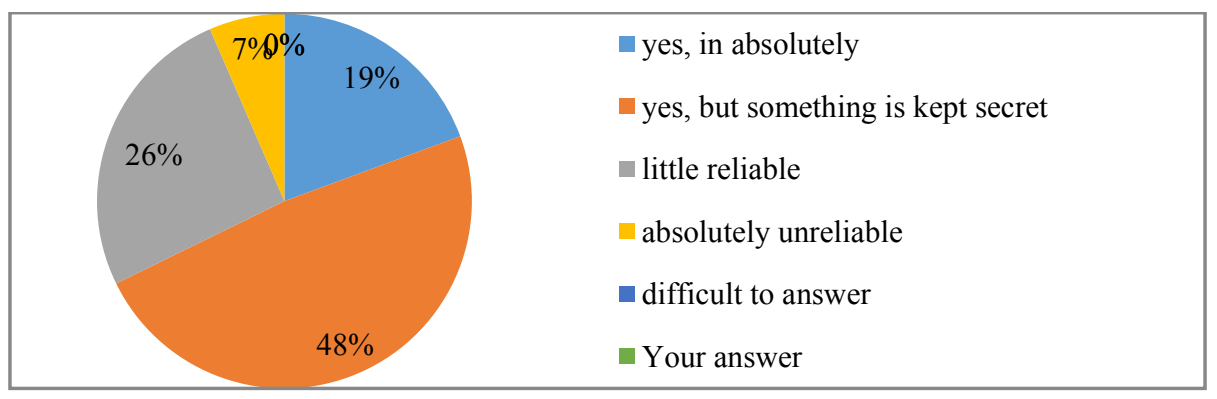

Fig. 3. The assessment of the reliability of information of the pandemic situation Source: own research, May 2020 
Block 2 - the comparative analysis of changes in the well-being of workers as a result of changes in specifics and working conditions of two groups of respondents: those working as usual, and those working remotely.

A) The assessments of changes in working conditions and work specifics of the respondents of both groups differ significantly. (Fig. 4a, 4b).

The most significant change in work specifics for those working as usual is the necessity to use protective measures ( 1 st place by importance), control of proper personal contacts ( $2 \mathrm{nd}$ place by importance) as well as the increase in stress-causing factors (3rd place by importance). (Fig. 4a)

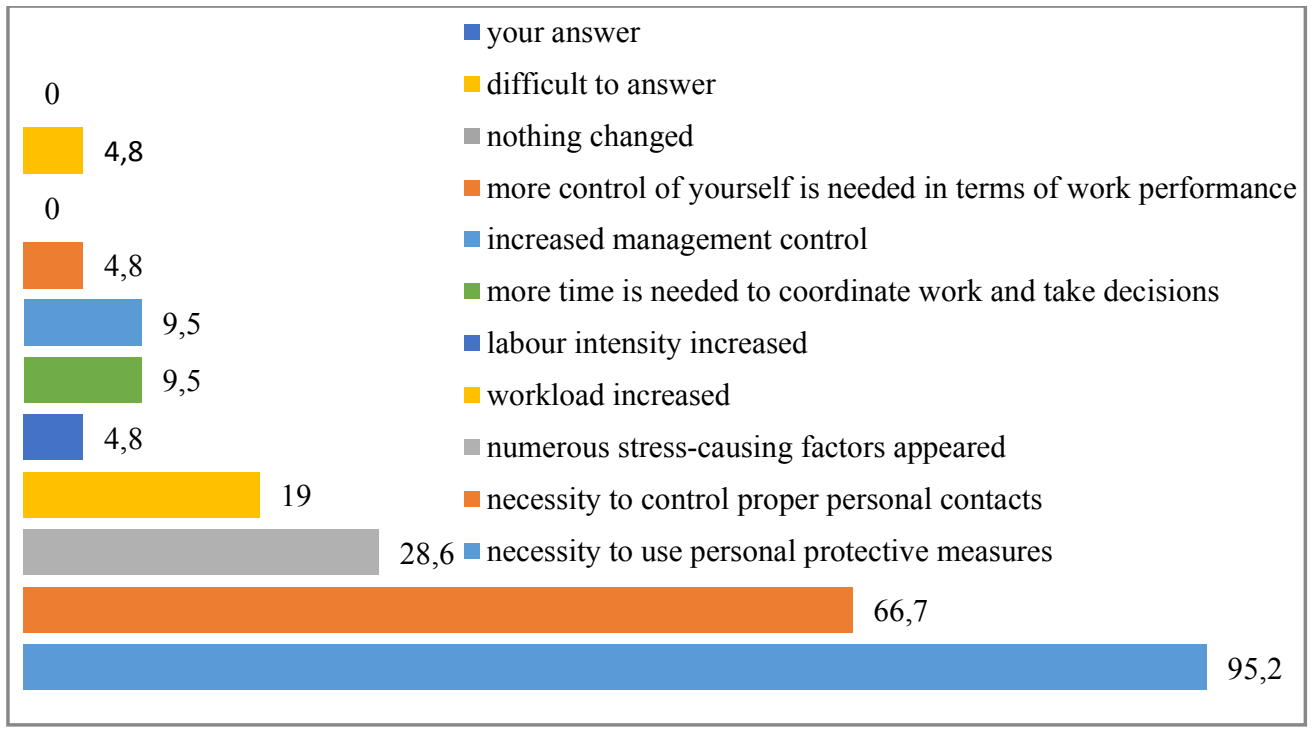

Fig. 4a. Changes in work specifics for those working as usual in the pandemic Source: own research, May 2020

The majority (40\%) of those working remotely found it difficult to answer, whereas one third (33\%) highlighted that nothing changed in specifics and conditions of work. (Fig. 4b)

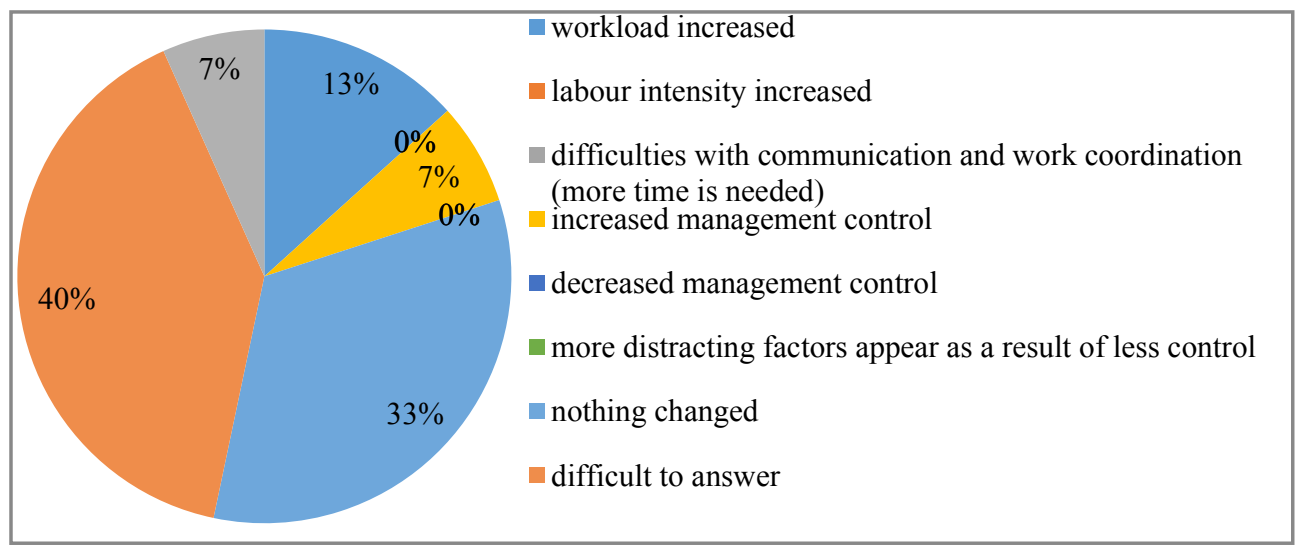

Fig. 4b. Changes in work specifics and conditions for those working remotely in the pandemic Source: own research, May 2020

B) The respondents of 2 eliminated groups - those working as usual, and those working remotely - assess the changes in their well-being differently. (Fig 5a, 5b). 
The majority of employees (57\%) working as usual note that well-being generally has not changed. However, almost one third (29\%) note little negative changes. (Fig. 5a).

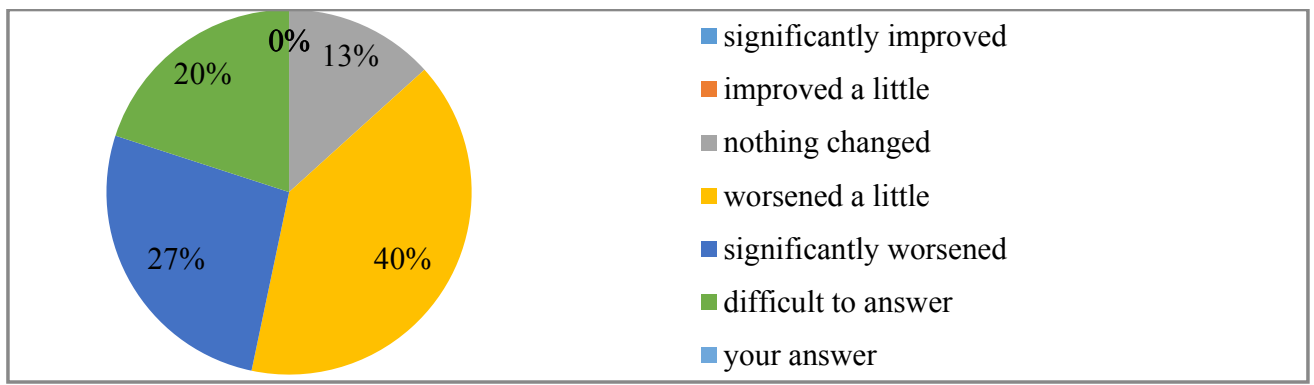

Fig. 5b. Assessment of changes in general well-being for those working remotely Source: own research, May 2020

C) The main changes in the material well-being of employees concerned the loss of part of their income. At the same time, more significant losses (up to $70 \%$ of income) are noted by the respondents working remotely in comparison with those working as usual (up to $50 \%$ ). (Fig. 6a, 6b)

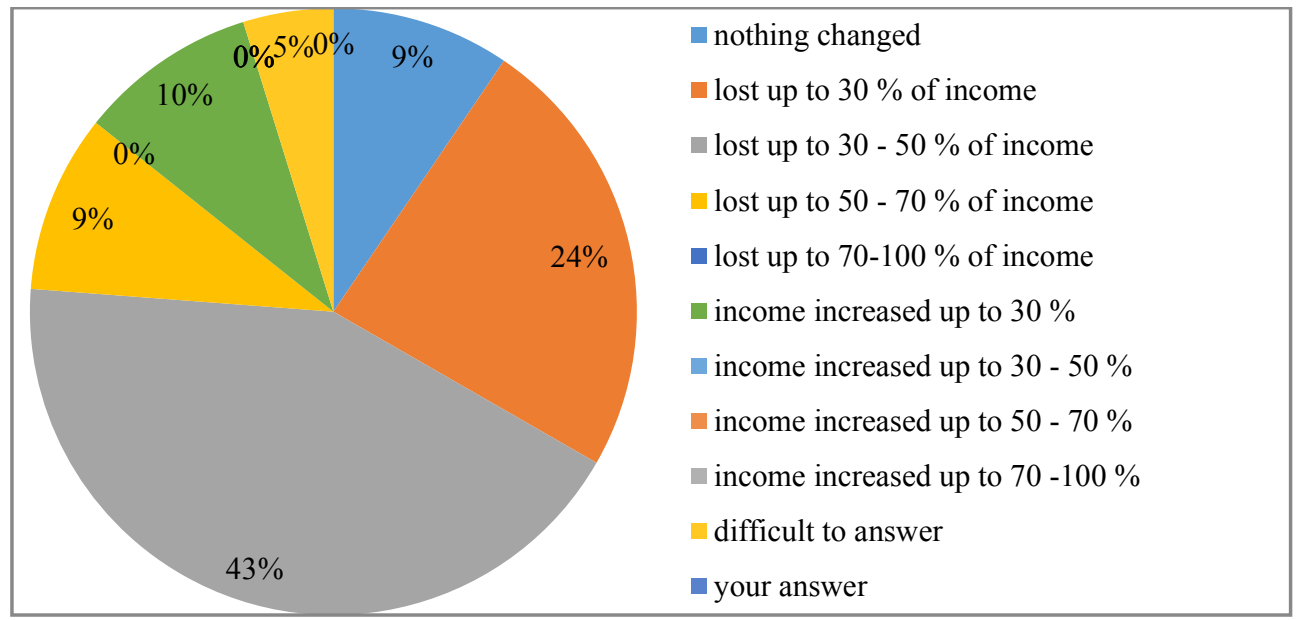

Fig. 6a. Assessment of changes in general well-being for those working as usual Source: own research, May 2020

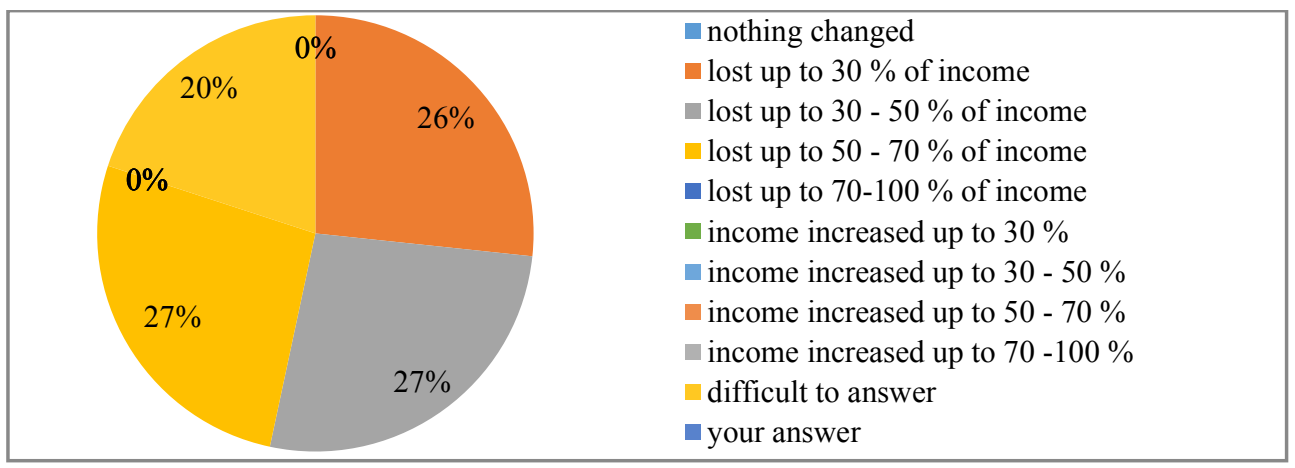

Fig 6 b. Assessment of changes in general well-being for those working remotely

Source: own research, May 2020 
D) The threat of redundancy due to the pandemic practically does not arise in any of the groups of respondents. (Fig. 7a, 7b)

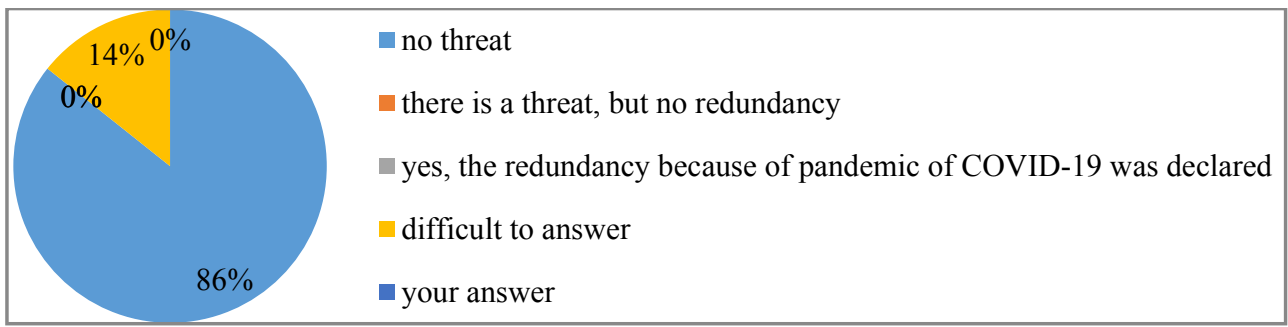

Fig. 7a. Assessment of the threat of redundancy due to the pandemic associated with COVID-19 working as usual

Source: own research, May 2020

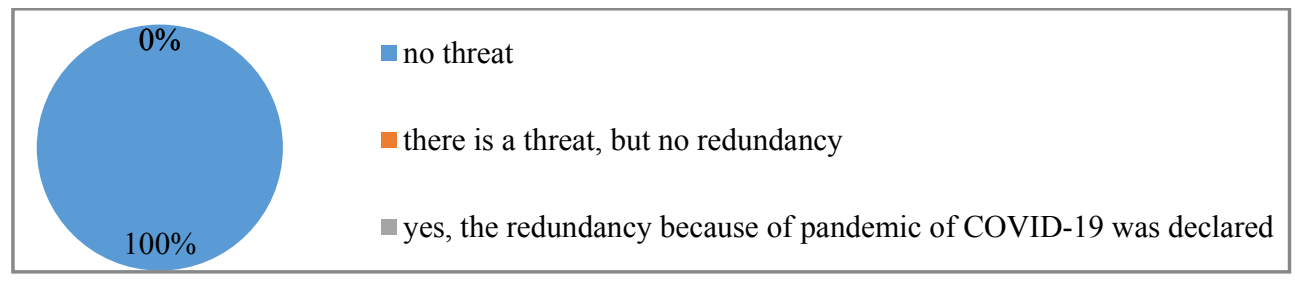

Fig 7b. Assessment of the threat of redundancy due to the pandemic associated with COVID-19 working remotely

Source: own research, May 2020

\section{Block 3 - changes in the specifics of remote work caused by the pandemic}

A) The specifics of working remotely relate mainly to an increase in labor intensity (40 $\%)$ and a weakening of control by management (13\%). However, one third of the respondents (33\%) report the lack of changes in typical modes when working remotely. (Fig. 8)

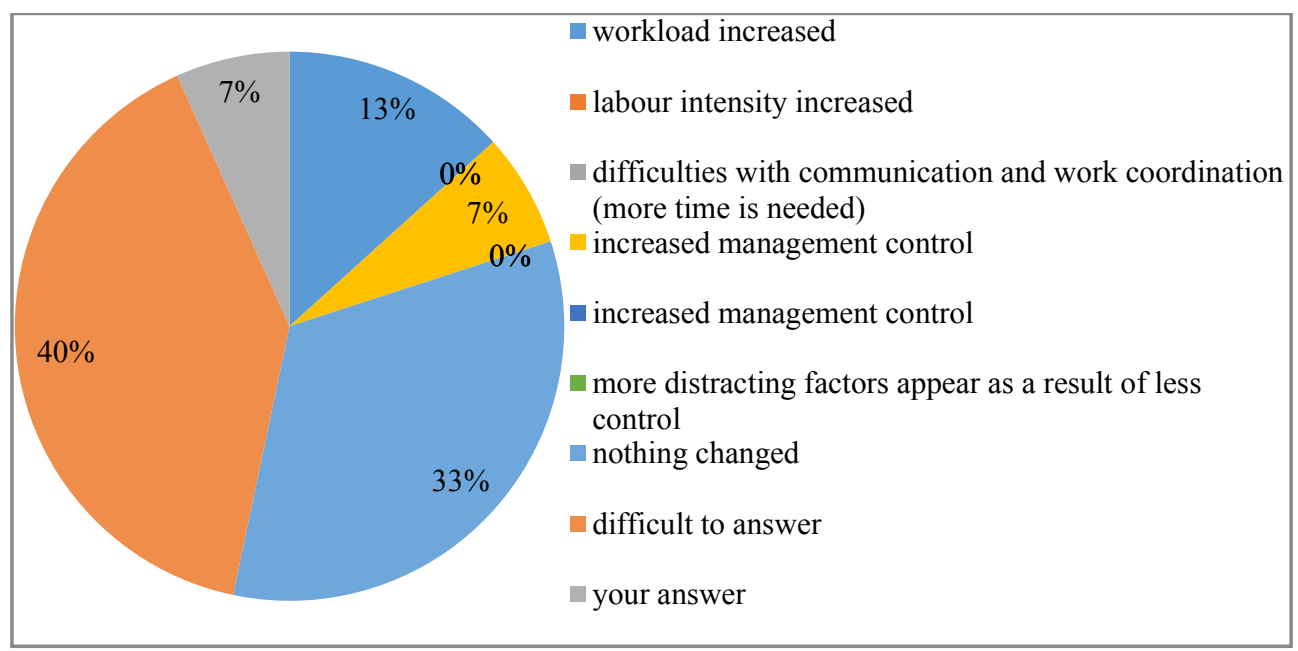

Fig 8. Assessment of the specifics of work when working remotely due to the COVID-19 pandemic Source: own research, May 2020

B) The intensity of the transition to working remotely shows a large differentiation of the respondents' opinions: for a third (33\%) of employees, the transition was accompanied by 
significant difficulties, for a third - without significant changes, and almost a third (27\%) found it difficult to assess. (Fig. 9)

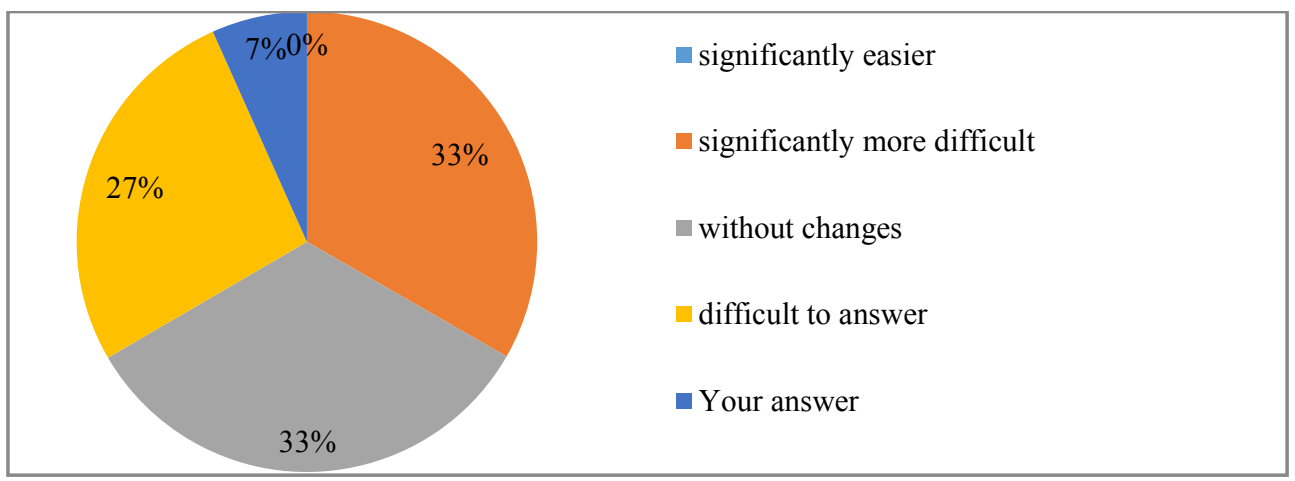

Fig. 9. Assessment of the changes in labour intensity during the transition to a remote work mode Source: own research, May 2020

C) Only about a quarter (22\%) of respondents see the reasons for alleviating labor tension in a pandemic in the ability to independently establish work and rest regimes in the process of performing work, whereas the overwhelming majority $(72 \%)$ of respondents find it difficult to answer, that is, they practically do not see such reasons. (Fig. 10)

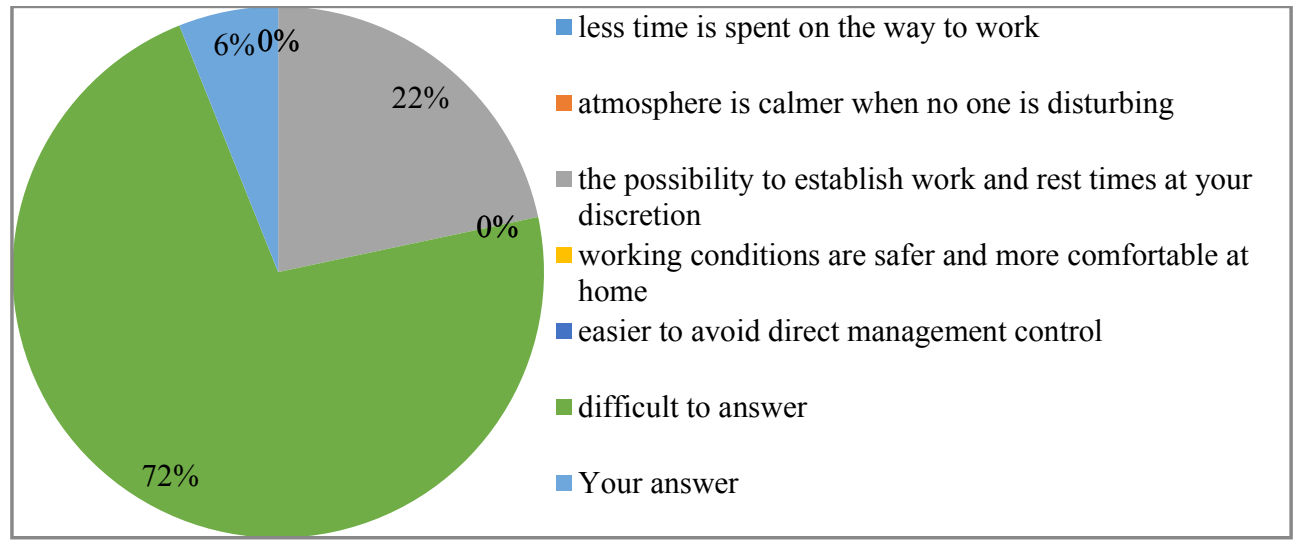

Fig. 10. The reasons for alleviating labor tension in a pandemic when working remotely Source: own research, May 2020

D) It is also difficult for respondents to assess the reasons for the difficulties of performing work remotely: only $20 \%$ point to one of them, namely, technical difficulties. The overwhelming majority ( $80 \%)$ of the respondents found it difficult to answer the question. (Fig. 11) 


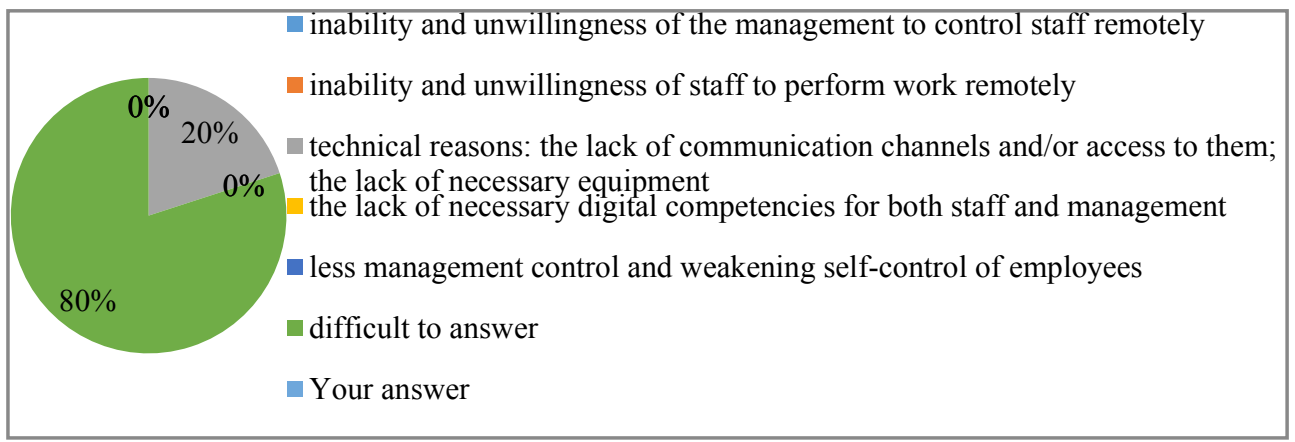

Fig. 11. The reasons for the difficulties of performing work remotely Source: own research, May 2020

E) The overall (final) assessment of the effectiveness of the organization as a whole when operating remotely is low: only $13 \%$ of respondents noted its growth. (Fig. 12)

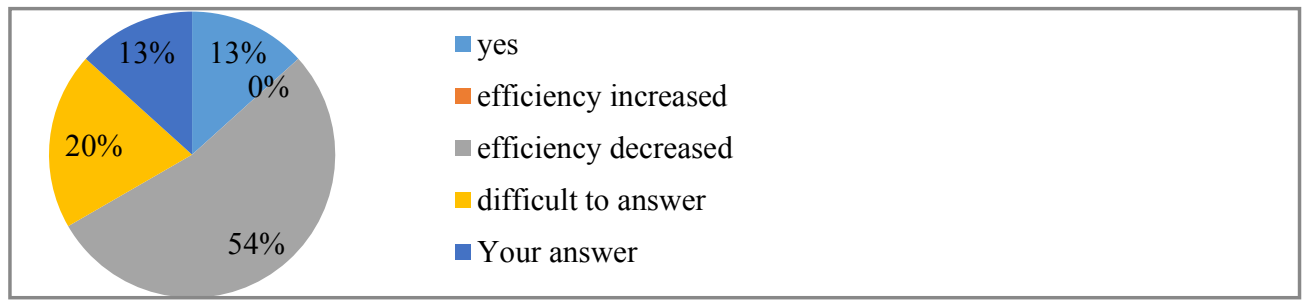

Fig. 12. The final assessment of the effectiveness of the organization after transition to working remotely

Source: own research, May 2020

\section{Discussion and conclusion}

The analysis of the results of the conducted study allows us to draw the following significant conclusions:

1) Full, timely and reliable informing of employees is an important factor influencing the productive work of personnel in extreme situations. The reliability factor acts as the most critical one in this regard. In our study, the respondents noted a high level of timeliness and a gradual decline in the level of completeness, and an even lower level of reliability.

2) The comparative analysis of employees' opinions working as usual and remotely differ dramatically. Despite the absence of threat of redundancy due to the pandemic situation, what is a positive factor, negative consequences - a decrease of well-being in general and a decrease of material well-being are reported mostly by the employees transferred to a remote work mode. At the same time, the latter reported unchanged specifics and conditions of work, or experienced difficulties describing them. Consequently, uncertainty has increased significantly for the employees working remotely in a pandemic situation.

3) Analysis of respondents' answers to questions about changes in the specifics of working remotely caused by the pandemic also shows the uncertainty of these estimates. The respondents do not have a clear idea of how to assess the changes that have occurred, both at the level of causes and at the level of effects.

Increasing uncertainty of activities encourages us to look for new ways and mechanisms of constructing labour algorithms as well as creating special working conditions for performing working activities in extreme situations caused by special living conditions in 
times of particularly dangerous deceases of pandemic scale. Further research in this area can significantly deepen the understanding of the tasks, principles and ways of responding to extreme situations affecting the world of work and industrial relations in order to reduce the level of uncertainty of work in order to achieve the most effective results in overcoming crises.

The work was supported by Act 211 Government of the Russian Federation, contract № 02.A03.21.0006; Russian Foundation for Basic Research (RFBR) under Grant № 19-010-00705 'Development of tools for assessing the impact of social pollution of labor relations on the employees' well-being in a digital economy'.

\section{References}

1. WHO (2020, March 11) WHO Director-General's opening remarks at the media briefing on COVID-19. WHO.

https://www.who.int/director-general/speeches/detail/who-director-general-s-openingremarks-at-the-media-briefing-on-covid-19---11-march-2020

2. Sohrabi, C., Alsafi, Z., O'Neill, N., Khan, M., Kerwan, A., Al-Jabir, A., Iosifidis, C., Agha, R. (2020). World Health Organization declares global emergency: Are view of the 2019 novel coronavirus (COVID-19). International Journal of Surgery, 76, 71-76.

3. Velavan, T.P., Meyer, C.G. (2020) The COVID-19 epidemic. Tropical Medicine \& International Health. 25(3), 278-280.

4. Spinelli, A., Pellino, G. (2020). COVID-19 pandemic: perspectives on nun folding crisis. British Journal of Surgery, 107(7), 785-787.

5. Dong, E., Du, H., Gardner, L. (2020). An interactive web-based dashboard to track COVID-19 in real time. Lancet Infectious Diseases, 20(5),533-534 .

6. Grasselli, G., Pesenti, A., Cecconi, M. (2020). Critical Care Utilization for the COVID19 Outbreak in Lombardy, Italy Early Experience and Forecast During an Emergency Response. Jama-Journal of the American Medical Association, 323(16), 1545-1546.

7. Rothan, H.A., Byrareddy, S.N. (2020). The epidemiology and pathogenesis of coronavirus disease (COVID-19) outbreak. Journal of Autoimmunity, 109, 102433.

8. Wax, R.S., Christian, M.D. (2020). Practical recommendations for critical care and anesthesiology teams caring for novel coronavirus (2019-nCoV) patients. Canadian Journal of Anesthesia-Journal Canadien Danesthesie, 67(5), 568-576

9. Treushnikova, N.V., Bachilo, E.V., Borodin, V.I., Antonova, A.A. (2020). Rekomendatsii dlya meditsinskikh rabotnikov nahodyashihsya $v$ usloviyah povishennih psihoemotsionalnih nagruzok $v$ period pandemii COVID-19 [Recommendations for medical workers under increased psycho-emotional pressure during COVID-19 pandemic]. Moscow: Scientific and educational centre of modern medical technologies.

10. Brunetto, Y., Xerri, M., Shriberg, A., Farr-Wharton, R., Shacklock, K., Newman, S., Dienger, J. (2020). The impact of workplace relationships on engagement, well-being, commitment and turnover for nurses in Australia and the USA. Journal of Advanced Nursing, 69(12), 2786-2799.

11. Heaney, C.A., Israel, B.A., Schurman, S.J., Baker, E.A., House, J.S., Hugentobler, M. (2020). Industrial-Relations, Worksite Stressreduction, And Employee Well-Being - A participatory action Research Investigation. Journal of Organizational Behavior, 14(5), 495-510. 
12. Merkulova, N.N. (2011). Sindrom emotsionalnogo vigoraniya i progtamma ego preodoleniya $\mathrm{v}$ sphere "pomogaushikh" professii [Burnout syndrome and a program for overcoming it in the field of "helping" professions]. Vestnik TGU, 12(104), 199-205.

13. Chumg, H.F., Cooke, L., Fry, J., Hung, I.H. (2015). Factors affecting knowledge sharing in the virtual organization: Employees' sense of well-being as a mediating effect. Computers in Human Behavior, 44, 70-80.

14. Bammens, Y.P.M., Yannick, P. M. (2016). Employees' Innovative Behavior in Social Context: A Closer Examination of the Role of Organizational Care. Journal of Product Innovation Management, 33(3), 244-259.

15. Xiang, Y.T. (2020). Timely mental health care for the 2019 novel coronavirus outbreak is urgently needed. Lancet Psychiatry, 7, 228-229.

16. Ermolaeva, S., Vishnevskii, Y., Nikonorowa, A. (2019). Practice of Employee Engagement Management at an Enterprise. In K.S Soliman (Eds.), Proceedings of the 34th International Business Information Management Association Conference IBIMA 2019 (pp. 2922-2930). Norristown: IBIMA 